Www.jmscr.igmpublication.org

Impact Factor (SJIF): 6.379

Index Copernicus Value: 79.54

ISSN (e)-2347-176x ISSN (p) 2455-0450

crossrefDOI: https://dx.doi.org/10.18535/jmscr/v6i11.105

Journal Of Medical Science And Clinical Research

IGM Publication

An Official Publication of IGM Publication

\title{
Original Research Article Study of Role of Ultrasound Guided FNAC of Right Hypochondrium Lump in patients, Attending in Tertiary Care Hospital at, S.K.M.C.H. Muzaffarpur, Bihar
}

\author{
Authors

\section{Dr Manoj Kumar ${ }^{1}$, Dr Manoj Kumar ${ }^{2}$, Dr Mahesh Prasad ${ }^{3}$, Dr Manju Geeta Mishra ${ }^{4}$ Dr Satyendu Sagar ${ }^{5}$} \\ ${ }^{1}$ Tutor, Department of Pathology, Sri Krishna Medical College, Muzaffarpur \\ ${ }^{2}$ Professor and HOD, Department of Pathology, Sri Krishna Medical College, Muzaffarpur \\ ${ }^{3}$ Associate Professor, Department of Pathology, Sri Krishna Medical College, Muzaffarpur \\ ${ }^{4}$ Director, M.G.M. Hospital, Patna \\ ${ }^{5}$ Assistant Professor, Department of Microbiology, Nalanda Medical College, Patna \\ Corresponding Author \\ Dr Satyendu Sagar \\ Assistant Professor, Department of Microbiology, Nalanda Medical College, Patna, India
}

\begin{abstract}
Objective: The aim of present study was the role of Ultrasound Guided FNAC of right hypocondrium lump and its comparative study with histopathlogical findings.

Material and Method: A total of 50 patients of different age groups of both sexes with presentation of right hypocondrium lump were referred from surgical and gynecological OPD for FNAC in our department were included in study. After thorough clinical history, all the patients were subjected to proper clinical examination. Prior to F.N.A.C. all the relevant routine investigation $(C B C, E S R, L F T$, KFT, BT, CT. Blood Sugar, Viral Markers) were performed and written consent were taken. After preparation of patient FNAC was done by $10 \mathrm{ml}$ syringe with 22 gauze needle in the presence of radiologist by Ultrasound Machine, Aspirated Materials were placed on grease free slide and fix. The entire fixed smear were stained by Giemsa and papanicolaou stain and examined under oil immersion microscope. After surgical removal of lump, histopathological examination was done and they were correlated with FNAC findings regarding accuracy of FNAC.

Results: Fine needle aspiration cytology was done in 50 patients from the palpable Right hypochondrium lump. The age distribution was up to 10 years in 2\% of cases, 11-20 years in 2\% of cases, 21-30 years in $8 \%$ of cases , 31-40 years 22\% of cases, $41-50$ years in 38\% of cases, $51-60$ years in 16\% of cases and 61 and above in $12 \%$ of cases. Out of 50 patients there are $28(56 \%)$ male and $22(44 \%)$ female. The commonest organ from where lump was aspirated is Liver followed by Gall bladder, kidney and stomach. The sex-ratio related with organ from where F.N.A.C. was done particularly in Liver and G.B. pathology related with liver in male $75 \%$ and in female $25 \%$ whereas pathology related with G.B. in male $17.6 \%$ and in female it was $82.4 \%$. The consistency of lump was soft in 5 cases (10\%), firm in 12 (24\%) cases and Hard in $33(66 \%)$ of cases. Out of 50 patients mild tenderness was present in 7 cases (14\%), Moderate in $34(78 \%)$ cases, Severe in 6 cases (12\%) and only 3 cases (6\%) was non-tender lump. The sufficient
\end{abstract}


material for Smear was obtained on Aspiration cytology of $88 \%$ of cases, Scanty with lesser number of cells in $4 \%$ cases and unsatisfactory in $8 \%$ of cases. Out of this cytological diagnosis Malignant lesion was found in $60 \%$ of cases, Benign in 16\%, Infective or in inflammatory in $16 \%$ of cases and $8 \%$ was undiagnosed. $68 \%$ of the Right hypochondrial lump were malignant and $32 \%$ were either Benign and inflammatory as found on histopathological examination. In the malignant Group 36 cases (68\%) diagnosed by histopathology where as 30 cases (60\%) were diagnosed cytological as malignant. The distribution of Malignant case by cytologically and histologically was, From Carcinoma Liver (secondary) 12 cases out of 18 malignant and 6 primary cases by both, same diagnosis carcinoma G.B. 8 cases out of 12 diagnosed cytologically and 12 cases by histologically diagnosed as malignant. Renal cell carcinoma 2 cases cytologically and histologically both found malignant. Lymphoma and Carcinoma stomach 1 and 1 cases found cytologically and histologically, malignant in distribution respectively. In liver out of 18 cases malignant diagnosed by cytologically 12 cases was secondary and 6 cases was Primary. The distribution of Benign lesion diagnosed by cytologically and histologically was as from, liver 3 benign and 3 infective or Inflammatory and from G.B. 5 benign lesion and 4 cases which consider under miscellaneous group were infective or inflammatory and 1 cases from L. N. consider as infective or inflammatory. So total $32 \%$ (16 cases) consider as benign out of 50 cases. The diagnostic accuracy of cytological Aspiration was $92 \%$ out of $60 \%$ malignant and $32 \%$ benign or infective and inflammatory lesion. The complication related with F.N.A.C. included as pain and discomfort in 09 cases (18\%) and post aspiration bleeding in 03 cases (06\%). There was no sepsis, peritonitis and injury to other visceral structure reported in follow up cases.

Conclusion: FNAC is simple, low cost, safety, painless and for the initial investigative and diagnosis of both superficial and deep lesion. The clinical value of F.N.A.C. is not limited to Neoplasitc condition but also valuable in the diagnosis of inflammatory, Infectious and degenerative conditions. It is also useful in the diagnosis and monitoring of graft rejection in transplantation surgery.

Keywords: FNAC, Right hypochondrium Lump, Histopathology, Geimsa Stain, Liver, Neoplastic.

\section{Introduction}

"Aspiration cytology is not a substitute for histopathology but is one of the weapons to be used to hit the diagnostic target." Right Hypochondrium lump or swelling is a common presentation in OPD with or without symptoms. Lump in Right Hypochondrium is associated with pathology of certain organ, which is affected. In anatomical classified Right hypochondrium. It is associated with Liver and its related pathology, Non-neoplastic, Neoplastic, Pancreas and G.B. and its related pathology. Pathology associated with Stomach, Pathology associated with Duodenum, and other parietal intra-abdominal and retroperitoneal pathological changes.

For proper management of a case of Right Hypochondrium lump, early and correct diagnosis is essential. No form of investigation can replace the clinical examination but it has own its limitations. So, the exact nature of any lump in the Right Hypochondrium is mandatory before any definite treatment. For acceptance of value of F.N.A.C., the clinician must overcome this prejudice that passing a thin needle into a malignant lesion will spread the tumor surely. This objective has not been sustained in the studies of thousands of cases. Rousel et al in 1989 and by Power in 1996 both reviews that the risk of needle track seeding is extremely less when truly fine needles of 22 gauge or less are used. Initially, the Pathologist working is insisting on sectioning as well as smearing the sample and would make a confident diagnosis if cell block preparation were obtained. Seeding of tumor cell in avascular planes, where they become resistant to radiotherapy or chemotherapy, recurrence of tumor at the site of biopsy scar, and need for local and general Anesthesia, morbidity, due to infection after biopsy, time and cost involved in it. 4 "Aspiration cytology was advocated and started by Martin and Ellis (1930) at the memorial hospital in USA and used needles of a thick caliber (18 gauges) than those common in use today. All these workers have emphasized its simplicity, low cost, safety, painless and for the initial investigative and diagnosis of both superficial and deep lesion. The clinical value of F.N.A.C. is not limited to Neoplasitc condition but 
also valuable in the diagnosis of inflammatory, Infectious and degenerative condition. It is also useful in the diagnosis and monitoring of graft rejection in transplantation surgery.

The present study has been proposed to evaluate the fine needle Aspiration Cytology as a diagnosis of Right hypochondrium lump in the abdomen. We have presented the analyzed and assessed result of cases from abdominal lump in the present study with following aims and objectives to find out the all reliability, Assessment of accuracy in relation to basic pathological process and to standardize the process of Aspiration of location and staining.

\section{Materials and Methods}

Present study was conducted in the Department of Pathology, Sri Krishna Medical College, Muzaffarpur, with the help of Department of Radiology, Surgery and Obstetrics and Gynecology, during the period of November 2016 to December 2017. A total of 50 patients, with different presenting complains and with right hypochondrial lump were seen in surgical and Gynecology OPD and were send for Ultrasound Guided F.N.A.C. in our department. From all the patient thorough present or past medical and surgical history were taken. Proper clinical examination was done. All the relevant routine investigation was performed in every case (CBC, ESR, BT, CT, LFT, KFT, and Blood Sugar. Viral markers and plain X-Ray abdomen etc). Written consent was taken from all the patients. F.N.A.C. was done by $10 \mathrm{ml}$. air tight disposable syringe with 23 gauze needle. Before to perform F.N.A.C. it is mandatory to inform the patients and explain them about the procedure.

After proper preparation the lump was palpated to determine its exact location and extent and after than fixed the lump with the help of left hand in a favorable aspiration position. Before to perform F.N.A.C. it is mandatory to inform the patients and explain them about the procedure.

Before inserting the needle the radiologist show the lesion site and size on the monitor screen with the help of probe the direction of needle is more or less same to the direction of probe. After that, the needle syringe was introduced vertically downward into the most prominent part of swelling.

Again we asked the radiologist to confirm that the needle is present inside the swelling or not. For this, they again placed the probe in close to needle syringe and confirm.

After that, the plunger was pulled to provide negative pressure. A few forward and backward to and fro movement of needle was made within the lump by maintaining the constant suction till some material appeared in the syringe or nozzle. After that the needle was withdrawn and the puncture site was pressed for 2 minutes and then sealed tincture benzoic swab.

The needle containing the aspirated material was detached from the syringe and reattached after pulling the plunge a back. The aspirated material was pushed out on a clean glass slide and spread it gently with the help of other slide and makes a smear. The smear of two slide were cover with one drop of span cytofixed which fixed the content in wet from and two slide smear was shaken in air to make a air dry smear specially for Giemsa staining and Staining of cytological smear by Giemsa method and Papanicolaou stain. After proper staining all the slide were seen under oil Immersion lens and report accordingly.

After surgery, incisional or excisional biopsy, was taken and histopathological examination was done. The histopathological diagnosis, thus obtained was considered the final diagnosis.

Finnally, the result of cytological diagnosis were compared with those of histopathological diagnosis, in order to evaluate the accuracy of diagnosis obtained by F.N.A.C., vis-a-vis histopathology. 


\section{Results}

Table-1 Shows maximum number of cases in the study is above the age of 41 or in between 41 to 50 age group.

\begin{tabular}{|l|c|c|}
\hline Age of Patients in Years & Total No. Patients & Percentage \\
\hline $0-10$ & 1 & $2 \%$ \\
\hline $11-20$ & 1 & $2 \%$ \\
\hline $21-30$ & 4 & $8 \%$ \\
\hline $31-40$ & 11 & $22 \%$ \\
\hline $41-50$ & 19 & $38 \%$ \\
\hline $51-60$ & 8 & $16 \%$ \\
\hline 61 and above & 6 & $12 \%$ \\
\hline Total & 50 & $100 \%$ \\
\hline
\end{tabular}

Table - 2 Shows the sex distribution in different age groups

\begin{tabular}{|l|c|c|c|c|}
\hline Age & \multicolumn{2}{|c|}{ Male } & \multicolumn{2}{c|}{ Female } \\
\hline & Total No. of Cases & percentage & Total No. of Cases & percentage \\
\hline 0-20 Years & 1 & $2 \%$ & - & - \\
\hline 11-20 Years & - & - & 1 & $2 \%$ \\
\hline 21-30 Years & 3 & $6 \%$ & 1 & $2 \%$ \\
\hline 31-40 Years & 5 & $10 \%$ & 6 & $12 \%$ \\
\hline 41-50 Years & 10 & $20 \%$ & 9 & $18 \%$ \\
\hline 51-60 Years & 4 & $8 \%$ & 4 & $8 \%$ \\
\hline 61 and above & & & & $44 \%$ \\
\hline Total & 28 & $56 \%$ & 22 & \\
\hline
\end{tabular}

The above table- 2 shows that the maximum percentage $(56 \%)$ cases in this study are male and $44 \%$ are female. But there is very less $2 \%$ difference in between male and female in the age group of 31-40 Years and 41-50 years in the Rt. hypochondrial lump related cases and in between Age group of 51-60 groups.

But in age group 61 and above there is marked difference in sex according to cases in between male and female.

Table-3 Shows about the consistency of lump in Right hypochodrium

\begin{tabular}{|l|c|c|}
\hline $\begin{array}{l}\text { Consistency of } \\
\text { Lump }\end{array}$ & $\begin{array}{c}\text { Total No. of } \\
\text { Lump }\end{array}$ & Percentage \\
\hline Soft & 5 & $10 \%$ \\
\hline Firm & 12 & $24 \%$ \\
\hline Hard & 33 & $66 \%$ \\
\hline Total & 50 & $100 \%$ \\
\hline
\end{tabular}

Table -4 Shows about the tenderness of the lump

\begin{tabular}{|l|c|c|}
\hline $\begin{array}{l}\text { Tenderness } \\
\text { of Lump }\end{array}$ & $\begin{array}{c}\text { Total No. of } \\
\text { Cases }\end{array}$ & Percentage \\
\hline Mild & 7 & $14 \%$ \\
\hline Moderate & 34 & $68 \%$ \\
\hline Severe & 6 & $12 \%$ \\
\hline Non-tender & 3 & $6 \%$ \\
\hline Total & 50 & $100 \%$ \\
\hline
\end{tabular}

Table-5 Shows materials aspirated in FNAC

\begin{tabular}{|l|c|c|}
\hline $\begin{array}{l}\text { Material on Aspiration } \\
\text { Cytological yield }\end{array}$ & $\begin{array}{c}\text { Total Number } \\
\text { of cases }\end{array}$ & Percentage \\
\hline $\begin{array}{l}\text { Sufficient material for } \\
\text { smear }\end{array}$ & 37 & $74 \%$ \\
\hline $\begin{array}{l}\text { Blood mixed fluid or } \\
\text { plus like material }\end{array}$ & 7 & $14 \%$ \\
\hline Scanty material & 2 & $4 \%$ \\
\hline Unsatisfactory & 4 & $8 \%$ \\
\hline Total & 50 & $100 \%$ \\
\hline
\end{tabular}

Table-6 Shows the different type of cells found on Aspiration Cytology

\begin{tabular}{|l|c|c|}
\hline Type of cell in cytology & $\begin{array}{c}\text { No. of patients in whom different } \\
\text { type of cell }\end{array}$ & Percentage \\
\hline Malignant & 30 & $6 \%$ \\
\hline Benign & 8 & $16 \%$ \\
\hline infective & 4 & $16 \%$ \\
or inflammatory & 4 & $8 \%$ \\
\hline undiagnosed & 4 & $100 \%$ \\
\hline Total & 50 & \\
\hline
\end{tabular}


Table - 7 (a) show malignant Rt. hypochondrium lump as by Aspiration cytology

\begin{tabular}{|l|c|c|c|c|}
\hline $\begin{array}{l}\text { Organ from Aspiration } \\
\text { was done }\end{array}$ & $\begin{array}{c}\text { Total No of } \\
\text { cases }\end{array}$ & $\begin{array}{c}\text { Malignant } \\
\text { lesion }\end{array}$ & $\begin{array}{c}\text { Percentage of } \\
\text { malignant lump }\end{array}$ & $\begin{array}{c}\text { Total of lump from } \\
\text { different organ aspiration }\end{array}$ \\
\hline Liver & 24 & 18 & $60 \%$ & $48 \%$ \\
\hline Gall Bladder & 17 & 8 & $26.66 \%$ & $34 \%$ \\
\hline Kidney (Rt.) & 2 & 2 & $6.66 \%$ & $4 \%$ \\
\hline Stomach & 1 & 1 & $10 \%$ & $4 \%$ \\
\hline Lymphoma & 2 & 4 & $10 \%$ & $8 \%$ \\
\hline Miscellaneous & 4 & - & - & \\
\hline Total & 50 & 30 & $100 \%$ & \\
\hline
\end{tabular}

Table - 7 (b) Show nature of Rt. hypochondrial lump as per Histology

Table - 7 (c)

\begin{tabular}{|l|c|c|}
\hline Nature of lump & No. of lump & Percentage \\
\hline Malignant & 34 & $68 \%$ \\
\hline Benign \& other & 16 & $32 \%$ \\
\hline & 50 & $100 \%$ \\
\hline
\end{tabular}

\begin{tabular}{|l|c|c|c|c|}
\hline Diseased organ & Malignant & Benign & $\begin{array}{c}\text { Inflammatory or } \\
\text { Infective }\end{array}$ & Undiagnosed \\
\hline Liver & 18 & 3 & 3 & - \\
\hline G.B. & 8 & 5 & - & 4 \\
\hline Kidney & 2 & - & - & - \\
\hline Stomach & 1 & - & - & - \\
\hline Lymphnode & 1 & - & 1 & - \\
\hline Miscellaneous & - & - & 4 & 4 \\
\hline Total & 30 & 8 & 8 & - \\
\hline
\end{tabular}

Table-8 Shows Comparative study in between male and female particularly pathology related to liver and G.B.

\begin{tabular}{|l|c|c|c|}
\hline $\begin{array}{l}\text { Pathology related to liver \& } \\
\text { G.B. }\end{array}$ & M & F & Total \\
\hline Liver & $18(75 \%)$ & $6(25 \%)$ & 24 \\
\hline Gall Bladder & $3(17.6 \%)$ & $14(82.4 \%)$ & 17 \\
\hline
\end{tabular}

Table-9 Shows complication after FNAC

\begin{tabular}{|l|c|c|}
\hline Complication & Total no. of cases & Percentage \\
\hline Pain and discomfort & 09 & 18 \\
\hline Post aspiration bleeding & 03 & 06 \\
\hline Sepsis & 0 & 00 \\
\hline Peritonitis & 0 & 00 \\
\hline Needle track implantation & 0 & 00 \\
\hline Injury to other structure & 0 & 00 \\
\hline Total & 12 & 24 \\
\hline
\end{tabular}

Table 10 Shows the comparison between cytological and histopathological examination of malignant lump

\begin{tabular}{|l|c|c|c|c|}
\hline Disease & $\begin{array}{c}\text { No of case } \\
\text { diagnosed } \\
\text { cytologically }\end{array}$ & $\begin{array}{c}\text { Suspicious ornoofcases } \\
\text { undiagnosed by } \\
\text { cytology }\end{array}$ & $\begin{array}{c}\text { Histologic ally } \\
\text { diagnosed }\end{array}$ & $\begin{array}{c}\text { Total cytological diagnosed + } \\
\text { cytological suspicious } \\
\text { for malignant }\end{array}$ \\
\hline Ca. liver secondary & 12 & - & 12 & 18 \\
\hline Ca. liver primary & 6 & - & 6 & 12 \\
\hline Gall Bladder Ca. & 8 & 4 & 12 & 1 \\
\hline Ca Stomach & 1 & - & 2 & 2 \\
\hline Renal cell carcinoma & 2 & - & 1 & 1 \\
\hline Lymphoma & 1 & - & 34 & 34 \\
\hline Total & 30 & 4 & 12 & 12 \\
\hline
\end{tabular}


In the table 10 showing that out of 50 the 34 Right hypochondrial aspiration lump are malignant. The total number of 30 cases are diagnosed, cytologically and 34 are by histopathologically. The 4 cases undiagnosed or suspicious for malignancy and it is to be later confirm by histologically that it was malignant.

Therefore the accuracy of aspiration cytology was $88.23 \%$ ( 30 out of 34 ) in the case of malignant Rt. hypochondrial lump.

\section{Discussion}

The present study has been proposed to evaluate the F.N.A.C. as a diagnosis of Rt. hypochondria intra-abdominal lump. Aspiration cytology was advocated and started by Martin and Ellix (1930) at the memorial hospital in U.S.A. Initially, clinical evidence was preferred to biopsy for diagnosis of every lesion. If a lump was supposed to be infected or cancerous. In 1801, Adams used excision biopsy and microscopy. During the next 100 years, knowledge and technique advanced and by 1950 the pattern of biopsy had been Incisional (Excisional Biopsy), Needle biopsy (Thr-cut or drill) and histopathological examination and FineNeedle aspiration cytology.

Among these mention methods the F.N.A.C. emerged as inexpensive, near painless and quick O.P.D. procedure. Even the deep lump within abdomen could be easily accessible by with the help of ultrasonography, C.T. Scan and other localizing devices.

The role of F.N.A.C. in the diagnosis of Righ thypochondrium and other site of intra-abdominal lump got wide popularity after 1930 by Martin and Ellis and began to flourish in 1950 and 1960 when Soderstorm, and Franzen in Sweden and Lopes Carnodoze in Holland studying. The thousand of cases poineer physician of this branch namely Paul Lpes Candoz (1964). Niles Soderstorm (1966) and Franzen (1968) and Zajicek 1968 at Kanolinska Institute Stockholm made considerable advancement in its technique with excellent result. They successfully brought it in routine practice by $1960-70$. This day it has been in routine use as preoperative diagnostic tool in abdominal lump.

The present study or series of work has been done on 50 patients of palpable Righ thypochondrial lump to aid in diagnosis of different lesion by aspiration cytology.

In the present study the F.N.A.C. was done in almost all age group. There is some variation in disease related with age group. The youngest patients in our study were 9 year and the oldest one was of 80 Years. Zorona et al in 1977 aspirated 159 patients among the age group of 6-8 Years. Goldstein et al in 1977 aspirated 17 patients in age group of 10-12 years. Ennis et all in 1980 aspirated 38 patients among the age group of 20-82 Years, Porter et al in 1981 aspirated 145 patients among the age group of 3-8 years. Montal et al. 1982 aspirated 176 patients among age group of 21-87 years. Swaroop at al in 1982 and Sunderam et al. in 1982. Schwerk et al in 1985, singh et al. 1984 had also done fine needle aspiration cytology among patient of different age group.

Age of patients varying in different age group in different series but the finding of the present series are more or less in confirmatory with that found by Ennis et al.

Age has not been found a contraindication against the institution of fine needle aspiration cytology procedure in diagnosis of Abdominal lump.

In our present study the maximum number of cases $19(38 \%)$ fall in between 41-50 age group followed by 11 cases (22\%) in between 31-40 age group, 8 cases $(16 \%)$ in between 60 age group and 6 cases $(12 \%)$ above the 61 age group. There are only 1 cases in between $0-10$ Year are group one present in our present series of study.

Out of 50 patients with Right hypochondrial lump in whom fine-needle aspiration cytology was done ,the total number of 28 cases $(56 \%)$ present in Male and 22 cases $(44 \%)$ are in female. In the present study in between age group 41-50 years the maximum number of male 10 cases (20\%) and maximum number of female 9 cases $(18 \%)$ are present. 
The difference in percentage in between male and female in the age group of 31-40 years and 41-50 years in the Right hypochondrial lump related pathology is very less only $2 \%$ difference in between both sexes.

But, in the age group of 61 and above there is markedly difference in percentage of pathology related with Right hypochondrial lump above 61 years there is 6 cases present in our study. Out of 6 cases 5 cases $(83.3 \%)$ present in male and 1 case $(16.7 \%)$ are present in female.

Therefore the table-2 shows that the Right hypochondrial lump related pathology in respect to sex also linked with age group and states that the difference is less in between 31 years to 50 years of age and After 61 yrs. the Right hypochandrial related pathology is more in Male in respect to female according to sex incidence in Right hypochandrial pathology.

In the present study, the consistency of Right hypochandrial lump hard in 33 cases (66\%), firm in 12 cases $(24 \%)$ and Soft in 5 cases $(10 \%)$ table3

In the present study out of 50 cases the 34 cases had moderate tenderness and 7 cases had mild and 6 had under severe tenderness only 3 cases (6\%) was non-tender in nature(Table-4).

In the present study aspirate obtained by Aspiration cytology for cytological study was sufficient in 37 cases (74\%) and blood mixed with pus or fluid in 7 cases. Out of 50 cases only in 2 cases there was scanty material yield and in 4 cases unsatisfactory yield aspirate. In the 4 cases (8\%) through the aspirate could be obtained but unsatisfactory due to insufficient cells were seen. In 7 cases the Blood mixed with pus or fluid is obtained shows the sufficient No. of cell when the fluid is centrifuged and smear is made on slide.

Thus the incidence of satisfactory cellular aspiration obtained in this study was $37+7$ cases total 44 cases and in percentage it was $88 \%$.The satisfactory smear sufficient for cytological study obtained by earlier workers was Zornoa et al. (1977) yield 94\% and sworop (1982) satisfactory cytology was $85 \%$.
A multifactorial cause are responsible for success or failure of the procedure. Mcloughlin et al. (1978) pointed out that the major limiting factor in a cytological Aspiration was the size of lump, failure of needle to enter into the lump and if bloody material not smeared thinly on slide, even after presence of highly suspicious cells, definite diagnosis of malignancy could not be made.

Present study also show the unsatisfactory aspirate in 4 cases $(8 \%)$.

In the present study out of 50 cases the 46 cases has the sufficient number of cell for diagnosis. Out of 46 cases 30 cases $(60 \%)$ were shows malignant cells, 8 cases (16\%) show benign in nature and 8 cases $(16 \%)$ infective or inflammatory in nature (Table-6).

Ennis et al (1980) showed out of 38 intra abdominal lump got malignant cells in 32 cases (84\%), inflammatory cells in 5 cases and cytological diagnosis was not possible in 1 cases.

In $8 \%$ cases of present study cellular diagnosis was not possible due to poor cellularity unrepresentative aspirate; Some possible technical error in smear preparation or staining.

Out of 50, the maximum number of lump aspirated from the Right hypochondrium were arising from the liver ( 24 cases) followed by Gall Baladder (17cases) then Rt. Kidney (2 cases) stomach (1 cases) and 1 lumps diagnosed as lymphoma. There are 4 lumps considered as miscellaneous due to structure superficial or deep intra-abdominal was related with Right hypochondrial.

In liver out of 24 lump originated 18 lump are diagnosed as malignant and 6 are benign 2 are hepatic abscess or infective lesion.

Out of 18 cases of malignant lump of Ca liver secondary in 12 cases and primary in 6 cases are diagnosed. In Gall bladder lump 17 cases was aspirated and out of 17 cases, 8 cases are malignant and remaining 5 cases are Benign or inflammatory lesion as diagnosed by cytologically and 4 cases are undiagnosed cytologically or suspicious lesion out of 1 lump from stomach diagnosed cytologically malignant, 2 lump from 
kidney diagnosed cytologically as Renal cell carcinoma and 1 lump as lymphoma.

Right hypochondrial lump arising from different viscera like liver, G.B. Stomach Rt. Kidney: Intestine, Pancreas lymph node had been aspirated by many worker like Ennis et. al. (1980); Porter et al. (1980) out of 38 our of 38 intra-abdominal lump. 18 cases from liver and diagnosed cytologically 16 as a malignant and 2 inflammatory lump from lymph node 8 cases 7 malignant 1 case of cytological failure Gall bladder 1 , cases diagnosed inflammatory lump rest was miscellaneous lump.

Wanni et al (1988) aspirated lump arising from liver (50) and diagnosed cytologically 34 cases
(68\%) as malignant and 16 cases no malignant cells were seen.

In the present study from the comparative study in liver given and G.B. Pathology related with sex show that out of total 24 aspiration from liver 18 cases in male $(75 \%)$ and 6 cases $(25 \%)$ present in female. Whereas in G.B. Pathology 14 cases $(82.4 \%)$ are in female out of 17 cases and 3 cases $(17.6 \%)$ in male.

In the similar fashion the liver pathology related to malignant in nature the secondary deposit in liver in 12 cases out of 18 and 6 cases is primary. In the present study the successful cytological diagnosis related with Right hypochendrial lump aspirated by F.N.A.C. under USG guided show the $92 \%$ whereas the other workers observed as

\begin{tabular}{|l|c|c|c|}
\hline Study in Year & $\begin{array}{c}\text { Study done by } \\
\text { Workers }\end{array}$ & $\begin{array}{c}\text { Successful cytological } \\
\text { diagnosis }\end{array}$ & $\begin{array}{c}\text { Unsuccessful cytological } \\
\text { diagnosis }\end{array}$ \\
\hline in 1977 & Goldstein et al. & $85 \%$ & $15 \%$ \\
\hline In 1980 & Zorenoze et al. & $83 \%$ & $17 \%$ \\
\hline In 1980 & Ennis et al. & $97 \%$ & $03 \%$ \\
\hline In 1981 & Philips et al. & $93 \%$ & $07 \%$ \\
\hline In 1982 & Sworop et al. & $85 \%$ & $15 \%$ \\
\hline In 1982 & Sundram et al. & $95 \%$ & $05 \%$ \\
\hline In 1984 & Singh et al. & $96 \%$ & $04 \%$ \\
\hline & Present Study & $\mathbf{9 2 \%}$ & $\mathbf{0 8 \%}$ \\
\hline
\end{tabular}

Singh et al (1984) got 96\% success without using image system which have been due to their better experience in cytological diagnosis.

The present series show successful cytological diagnosis in Rt. hypochondrial aspirted lump is $92 \%$ and unsuccessful in $08 \%$ cases. Correlate with ennies et al 03\% (1980) phillips et al $07 \%$ (1981) sundram et al 05\% (1982) and Singh et al $04 \%$ (1984) of unsuccessful rate and success rate of $97 \%, 93 \%, 95 \%$ and $94 \%$ respectively.

In the present study accuracy of F.N.A.C. was $88.23 \% 30$ out of 34 cases in malignant Rt. hypochandrial lump, (Table-10).

Out of 30 cases, 12 cases from the $\mathrm{Ca}$ liver secondary and 6 cases from primary total 18 cases out of $30(60 \%)$ are diagnosed as Ca liver but secondary in $66.66 \%$ (12 out of 18) and primary in $33.33 \%$ (6 out of 18 ) diagnosed by F.N.A.C.
Secondary metastatic in liver was diagnosed by laundanist et al 1970-78\% over $90 \%$ accuracy was obtained by Tao et al (1980).

In the present series out of 12 cases 8 cases are diagnosed cytologically $\mathrm{Ca}$ of Gall bladder (66\%), 1 case of $\mathrm{Ca}$ stomach and 2 cases of Renal cell carcinoma from out of 2 cases $(100 \%)$, and lymphoma (50\%) out of 2 cases.

In the present study the percentage of diagnostic F.N.A.C. for the malignant Right hypochondrial lump was $88.23 \%$ and it correlate with the finding of other worker like Hee et al (1978)- 85\% and ferucci wittenberg in 1978-85\%.

In the cases of Renal cell carcinoma 2 cases out of $2(100 \%)$ diagnosed as malignant by cytologically. The higher diagnostic accuracy observed in the present series it is due to lesser number of cases aspirated.

Many worker like Goldstein et al. (1977) Kline et al. (1978) Porter et al. (1980) Singh et al. (1984) 
and Ashok et al. (1986) did F.N.A.C. of Renal lump and they got varying accuracy from $68 \%$ to $100 \%$.

In the present series it is $100 \% 2$ cases out of 2 found Renal cell carcinoma due to lesser no. of case aspirated.

The diagnostic accuracy of lymphoma (Table-7.a) and (Table-10) is 50\% 1 case out of 2 in the present series.

Zornaza et al (1977)-64\% leukeman et al. (1977)64\% Ruttiman and wallace et al. (1975) and Goldstain et al. (1977)-77\% Pester et al (1981) said that lumphoma was difficult to diagnose accurately by F.N.A.C. and this view was also supported by the Hauge et al (1979). Staab et al. (1979) and ferrucci and Wittenberg (1980).

Table- 6 and Table-7.c show the nature of benign and infective or inflammatory Cytological diagnostic accuracy in different organ. In liver out of 24 aspirated cases 3 cases are benign (12.5\%) and 3 cases are of infective in nature. In the case of G.B. 5 cases out of $17(29.41 \%)$ are diagnosed benign in nature by F.N.A.C. and 4 cases $(23.8 \%)$ are undiagnosed by F.N.A.C. in the case of L.N. 1 out of 2 cases are diagnosed as infective (50\%) and also 4 miscellaneous group comes from the parietal and deep muscular or abdominal swelling are also diagnosed as infective or inflammatory lesion (1005) (Table 7.c).

In the present study 4 cases are cytoligically undiagnosed $(8 \%)$ due to unsatisfactory smear or material.

In the present study as shown in table-9 $18 \%$ patient felt pain and mild discomfort and $06 \%$ post aspiration bleeding at the puncture site, it was minor and stopped by manual pressure.

There was no sepsis, peritonitis needle tract seeding and injury to adjacent viscera structure in follow up cases. Some observer also observed that there was no complication of F.N.A.C. of intra abdominal lump were oscorson et al. (1972) foreign et al. (1973 Smith et al. (1975) tyelenetal (1976) Zornoza et al. (1977) Poster et al. (1981). Engzell et al. (1971) and Poster et al. (1981). Roussel et al (1989) and by Power in 1996. review that risk of needle tract seeding with extremely, low with less than 22 gauge Ferruci et al (1980): Muller et al (1981) mention the contra indication to needle aspiration like bleeding disorder and advised to correct this before F.N.A.C. perform. They also mentioned that Hydatid cyst is an absolute contraindication. So, it was advised not to do F.N.A.C. in these cases to avoid complication.

In the present study the Pain felt by the patient was due to Previously tenderness in Right hypochondrium or due to actual forward and backward movement of the needle and bleeding was also due to traumatic sequel of fine needle aspiration cytology.

In the present study did not encounter any serious complication after F.N.A.C. but it is agreed on the basis of theoretical ground that F.N.A.C. should be contraindication in bleeding diathesis, highly vascular lesion, hydatid cyst etc. of it suspected on clinical or other investigation ground.

Ashok et al (1986) advised not to aspirate spleen due to chances of bleeding or hydronephrotic kidney due to chances of infection and hydatid cyst due to chances of anaphylaxis.

\section{Conclusion}

The present series of study "Ultrasound Guided F.N.A.C. study of Rt. hypochandrium lump and its evaluation" is a useful diagnostic investigation for most of the palpable Rt. hypochondrium lump. It should be regarded as a very important Preoperative and Pretreatment investigation of Pathological process in combination with clinical, radiological and other laboratory data. In the present series the diagnostic accuracy is $92 \%$ as compared with histopatholocial diagnosis which provide $100 \%$ F.N.A.C. or fine needle aspiration cytology is found simple, inexpensive, even bed side or O.P.D. procedure, which can be performed without general anesthesia or without serious complication and with a speedy result with a maximum accuracy. 


\section{Reference}

1. S. Ashok and Agonwal SB (1986) U.S. guided F.N.A.C. of Intra-abdominal mass. J. (Sung) 48.10.11.

2. A Singh and N. Diwan (1984) : F.N.A.C. in the diagnosis of lump in the abdomen (I.J. Sungerj) 46-260-269.2

3. Ehud M (1984) Rare complication after Tran-abdominal five needle aspiration. Am Jenner Gastrocenterlogy 6.85-60

4. Eriksson (1984) Effect of F.N.A.C. on Flemon dessiminetion it mice cancer 5473-78.

5. Ferucci Jr-P Wittenberg J. (1981) Diagnosis of spelomihal malignancy by rediologically fine - needle aspirtion biosphy. Am Tr. Radiol - 134 - 323-330.

6. Thomson-P Thin needle aspiration biopsy Acta. Cytol- 26.262-263 (1982)

7. Soderstorm N. - (1980) Thin Needle aspiration biopsy Acta-Cytol 24-468;

8. Frable W.J. Needle aspiration biopsy : Poster present and futem Human Pathology 20-504-517 (1989).

9. Nosher J.L. and Plafker J. (1980) F.N.A.C. Aspiration of liver with ultrasound guided radiology 136.

10. Landquist A (1971) F.N.A.C. biopsy of liver, Acta medical scandivavica 250:1: 28.

11. Fersgren L and Bell (1973) : Aspirtion cytology in Carcinoma of the Pancreas.

12. Harvey M. (1977) Percutaneous fine needle aspiration biopsy of pancreatic and other abdominal masses Radiology 122 : 112-15;

13. KP Jamsen P \& Swendsen (1978) Scan guided fine needle aspiration biopsy in malignant hepatic disease Acta cytological, 22, 292-296.
14. Jaquos P Stab, R. Richey W (1978) : C.T. assisted Pelvic and abdominal aspiration biopsy in gynaecological malignancy Radiolagy 128 : 651-655.

15. Libraghi (1977) Raisk in fine needle Aspiration biopsy of Pancreatic and other abdominal masses. Radiology 123 : 319322

16. Meloughlin, J.J. et al. (1978). Fine needle Aspiration biopsy of Malignant lesion in the around the paucreas. Cancer. 41-241319

17. Mueller P.R. wilenberg J (1981) : Fine needle Aspiration biopsy of abdominal masses, Semen Roentegenol 16:15-61. 